\title{
Investigation on Parental Involvement: A Case Study of Teaching Shanghainese in
Shanghai Kindergartens
}

\author{
Yan-Yan LI \\ Tianhua College \\ Shanghai Normal University \\ Shanghai, China \\ leeyeanyean@126.com
}

\begin{abstract}
The aim of this study was to examine parental involvement of teaching Shanghainese in Shanghai kindergartens and to recommend the further promotion of parental involvement, in efforts to maintain and develop minority languages or Chinese dialects in China. Case study approach was used and Qing Kindergarten was the school chosen for this study. The results suggested that parental involvement play a significant role in promoting the teaching of minority languages or Chinese dialects at schools. However, there is much more that needs to be done for schools to enhance parental involvement, such as the increasing quality contacts, establishing a stronger relationship with parents, soliciting and responding to parents' suggestions and concerns, and empowering parents.
\end{abstract}

Keywords-parental involvement; teaching Shanghainese; kindergarten

\section{INTRODUCTION}

In recent years, China has seen a lot of changes that have influenced language learning, including the influences on Shanghainese, minority languages, and other local dialects in China. These changes include but are not limited to the promotion of Putonghua and an increase of people migrating to urban areas to obtain better education and job opportunities. An increasing number of young people are not able to speak their minority languages or local dialects in China.

Political, social, and demographic factors, as well as cultural and linguistic ones have caused a language shift, even the death of some languages[1]. However, language lies at the heart of education, culture, and identity. When a language dies, so does a considerable amount of the culture, identity, and knowledge that has been passed down from generation to generation. This also appears to minority languages or Chinese dialects. Therefore, the teaching of minority languages or Chinese dialects is beneficial and worth trying to implement or expand upon.

In efforts to preserve minority languages or local dialects, the Chinese government started to encourage the teaching of minority languages or Chinese dialects at schools as a way of maintaining and developing these culturally important speaking methods.
Parental involvement is increasingly viewed as an important mean to support better learning outcomes for children. When schools and parents work together, children have higher achievement in school and stay in school longer[2] Various definitions of parental involvement have been proposed. For the purpose of this paper, it can be defined broadly as parental behavior with, or on behalf of children, at home or at school, as well as the expectations that parents hold for children's future education[4].

The aim of this study is to examine parental involvement of teaching Shanghainese in Shanghai kindergartens and to recommend the further promotion of parental involvement, in efforts to maintain and develop minority languages or Chinese dialects in China.

\section{METHODS}

A case study seemed to be the best choice for learning more about this topic. In order to reveal the whole picture of parental involvement in the teaching of minority languages or local dialects at schools in China, the author employed a case study. The Shanghai government started teaching Shanghainese in 20 public selected kindergartens in September, 2014 as a trial. Among them Qing Kindergarten was one of those schools and was chosen for this research. Sources of data included observations, audio-recorded interviews, and documents on teaching Shanghainese.

\section{PROCEDURE}

In this study, the author employed in-depth interviews with two kindergarten teachers, one principal and two parents (one native Shanghainese and another New Shanghainese) in Qing Kindergarten. Each interview was about an hour long. The author did two follow up interviews for the kindergarten teachers and one follow up interview for the principal and the parents. Follow up interviews increased the amount of data for this as it was directly related to parental involvement in teaching Shanghainese.

\section{RESULTS}

Qing Kindergarten focuses on the development of basic mathematical skills. Principal Wen is in charge of teaching Shanghainese in the kindergarten. There are 45 teachers and 
560 children in Qing Kindergarten. Teachers are all native Shanghainese and of the majority of children are also native Shanghainese. Of these children, $78 \%$ have parents who are both native Shanghainese, $11 \%$ have one native parent, and $11 \%$ have parents who are New Shanghainese(Fig.1). New Shanghainese refer to the immigrants who moved to Shanghai from other areas of China.

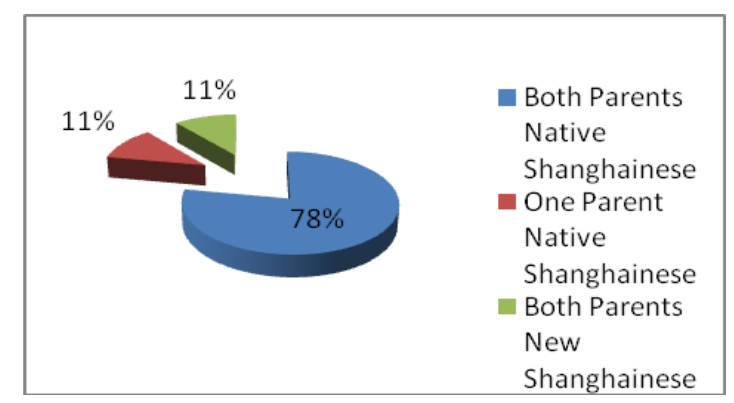

Fig. 1. Dialect Background of Parents

Parental involvement played a crucial role in teaching Shanghainese in Qing Kindergarten. Qing Kindergarten included parents in the teaching of Shanghainese by means of the PTO, parents as volunteers, activity-driven participation, and the assigning of homework (TABLE I).

TABLE I. WAYS OF PARENT AL INVOLVEMENT

\begin{tabular}{|c|c|c|l|c|}
\hline & \multicolumn{4}{|c|}{ Parental Involvement } \\
\hline $\begin{array}{c}\text { Kindergarten } \\
\text { Qing }\end{array}$ & PTO & $\begin{array}{l}\text { Parents as } \\
\text { volunteers }\end{array}$ & $\begin{array}{l}\text { Activity-driven } \\
\text { participation }\end{array}$ & $\begin{array}{l}\text { Assigning } \\
\text { homework }\end{array}$ \\
\hline
\end{tabular}

A. РTO

First, the PTO(Parents and Teachers Organization) was given questionnaires in September 2013 to investigate the parents' views and asked them to give suggestions regarding teaching Shanghainese. The results were analyzed and further used to guide the teaching of Shanghainese. The analysis showed that the majority of the parents had a positive attitude in regards to teaching Shanghainese in the kindergarten. The parents also suggested that the kindergarten should teach the children some daily use of Shanghainese, organize some activities with the dialect, and etc. This guided teaching Shanghainese in Qing Kindergarten. In addition, the PTO collected the ballads in Shanghainese voluntarily. With the efforts made by the parents, many ballads in Shanghainese were collected and most of them were put into use in the class.

\section{B. Parents as Volunteers}

Parents volunteered to assist teachers in teaching Shanghainese in the class. Parents and grandparents were invited to tell stories in Shanghainese or perform Huju, etc. There once was a graceful grandmother who was a famous woman in the social circles of Old Shanghai. She brought a picture of herself. She was wearing a beautiful chi-pao and told children how women behaved in Old Shanghai between 1912 and 1949.

Women in Old Shanghai were well-mannered, elegant, gentle, fashionable and feminine. I usually prepared three dresses for one day. I wore a short-sleeved sweater in the morning, a chi-pao for going out in the afternoon, and a Western styled long dress for entertaining visitors at night. My parents educated me on the importance of a balanced diet. The time for breakfast, afternoon tea, and dinner were all rigorously observed. I was not allowed to play with tableware at the table nor talk with food in my mouth. If the soup was hot, I was told not to use my mouth to blow on it.

When the grandmother was telling her story, the children were listening attentively, some even with their mouths open. It demonstrated that the children understood and were interested in the story. Those children whose parents were invited to the class were particularly excited about that. One native Shanghainese parent, Zhu, stated, "My son was proud to see me show any talents in front of his classmates. After I performed Huju in his class, my son seemed to have more interests in speaking Shanghainese at home."

Also, five parents volunteered to go to the kindergarten in every morning. They would help the teachers to wash the children's hands and clean the classroom. During this time, the parents spoke Shanghainese to the children.

\section{Activity-driven Participation}

The parents were invited to participate in some activities organized in Qing Kindergarten related to teaching Shanghainese. For example, the activity called "Experiencing Shanghainese" was held on December $29^{\text {th }}, 2014$. More than 300 children and parents were involved. Many children were singing at Bailemen (a famous entertainment club in Old Shanghai), while other children were playing some of the Old Shanghai alley games. A boy invited a parent to play Iron Ring Rolling with him. Some girls were jumping rope with a parent. The girls were singing ballads in Shanghainese while they jumped rope.

The parents were very happy to see their children were speaking Shanghainese and both the children and the parents reported they had a wonderful time together. As a New Shanghainese parent, Luo, stated:

I was so amazed to see my daughter could communicate with others in Shanghainese. I have been trying to learn some Shanghainese since I came to Shanghai. Unfortunately, I could not make it. Now I think my daughter can help me to accomplish this task.

Another activity of "Parents and Children Singing Songs in Shanghainese and Playing Games Together” was held once during the semester. Parents were invited to sing ballads in Shanghainese with the children, to tell stories in Shanghainese, to perform dramas and Huju in Shanghainese, to play games with the children, etc. There was a competition called "We are Shanghainese”, in which parents and grandparents sang songs in Shanghainese and performed the famous Huju, Seeds of Reed Marshes, with their children. Children took this opportunity to show and practice their Shanghainese.

\section{Assigning Homework}

The parents were also assigned homework. For example, Kindergarten Qing prepared and distributed some handouts for learning Shanghainese at home. The handouts included 
material such as some situational Shanghainese phrases, 10 sentences for daily use of Shanghainese, food names in Shanghainese. The children were happy to learn Shanghainese with their parents. As Teacher Xu stated:

There once were a couple of parents, who were both New Shanghainese. They worked in a company where the majority who spoke Shanghainese. Thus, they had to learn how to speak Shanghainese. They are happy to learn Shanghainese with their children through the help of the handouts. Children feel happy too.

In addition, parents were asked to encourage taking their children on fieldtrips within Shanghai, such as to the Oriental Pearl Building, Shikumen, and Chenghuang Temple. There is a great museum underneath the Pearl Building with all the replicas of old Shanghai streets. There were six scheduled field trips to visit different sites in Shanghai and parents were encouraged to join their children on the trips. After these fieldtrips, the children shared the pictures and their thoughts on WeChat, a social media application similar to Twitter. In this way, the children got to know more about Shanghai and its culture.

To sum it up, Qing Kindergarten got parents involved in teaching Shanghainese in the ways above, so that the meetings with the parents increased. Parents were even expected to have more activities relative to teaching Shanghainese. Both native and New Shanghainese parents greatly contributed to their children learning Shanghainese. Also parents gained trust and a stronger relationship with the kindergarten.

\section{Conclusions}

As a whole, the parents were more actively involved in teaching Shanghainese and were positive towards it. Many parents, including New Shanghainese parents, were strongly aware of the importance of teaching Shanghainese. In regards to the teaching of minority language or Chinese dialects at schools in China, a joint effort needs to be made between the schools and parents. When parents are involved, the schools can feel the support for the same learning goals.

The frequency of contact between the parents and the school can foster a relationship, the quality of the contact makes a larger difference. Schools should highly value their friendly ties with parents and promote parental involvement, which enhance mutual trust and boost collaboration of teaching Chinese dialects. Schools should establish a stronger relationship with parents and also solicit and respond to parents' suggestions and concerns. In order to increase parental involvement, especially for those parents who are most alienated by traditional schooling practices, schools should ask themselves what they can do to make parents feel more confident and comfortable with involvement and to provide the activities and resources that parents need to feel empowered[3].

It is hoped that parents will pay full attention to their role as a bridge between learning at home and learning at school as well as proactively contributing to the teaching of minority languages or Chinese dialects in China.

\section{REFERENCES}

[1] Conklin, N. \& Lourie, M. (1983). A Host of Tongues. New York: The Free Press

[2] Henderson, A. T., \& Mapp, K. L. (2002). A new wave of evidence: The impact of school, family and community connections on student achievement. Austin, TX: South-west Educational Development Laboratory.

[3] Hoover-Dempsey, K. V. Walker, J. M. T., Sandler, H. M., Whetsel, D., Green, C. L., Wilkins, A. S., \& Closson, K. E. (2005). Why do parents become involved? Research findings and Implications. The Elementary School Journal, 106(2), 105-130.

[4] Reynolds, A., \& Clements, M. (2005). Parental involvement and children's school success. In E. N. Patrikakou, R. P. Weissberg, S. Redding, \& H. J. Walberg (Eds.), School-family partnerships: Promoting the social, emotional, and academic growth of children (pp. 109-127). New York: Teachers College Press. 